\title{
Comparative Study of Biological Activities of Venom from Colubrid Snakes Rhabdophis tigrinus (Yamakagashi) and Rhabdophis lateralis
}

\author{
Yumiko Komori ${ }^{1, *}$, Toru Hifumi ${ }^{2}$, Akihiko Yamamoto ${ }^{3}$, Atsushi Sakai ${ }^{4}$, Manabu Ato ${ }^{5}$ (D), \\ Kyoko Sawabe ${ }^{6}$ and Toshiaki Nikai ${ }^{1}$ \\ 1 Department of Microbiology, Faculty of Pharmacy, Meijo University, 150 Yagotoyama, Tenpaku-ku, \\ Nagoya 468-8503, Japan; nikai@meijo-u.ac.jp \\ 2 Emergency Medical Center, Kagawa University Hospital, 1750-1 Ikenobe, Miki, Kita, Kagawa 761-0793, \\ Japan; hifumitoru@gmail.com \\ 3 Department of Biosafety, National Institute of Infectious Disease, Gakuen 4-7-1, Musashimurayama, \\ Tokyo 208-0011, Japan; yama-aki@niid.go.jp \\ 4 The Japan Snake Institute, Yabuzuka 3318, Ota, Gunma 379-2301, Japan; snake-b@sunfield.ne.jp \\ 5 Department of Immunology, National Institute of Infectious Disease, Toyama 1-23-1, Shinjuku, \\ Tokyo 162-8640, Japan; ato@nih.go.jp \\ 6 Department of Medical Entomology, National Institute of Infectious Disease, Toyama 1-23-1, Shinjuku-ku, \\ Tokyo 162-8640, Japan; sawabe@nih.go.jp \\ * Correspondence: ykomori@meijo-u.ac.jp; Tel.: +81-52-839-2732 \\ Academic Editor: Frank S. Markland \\ Received: 23 August 2017; Accepted: 15 November 2017; Published: 17 November 2017
}

\begin{abstract}
Rhabdophis lateralis, a colubrid snake distributed throughout the continent of Asia, has recently undergone taxonomic revisions. Previously, Rhabdophis lateralis was classified as a subspecies of R. tigrinus (Yamakagashi) until 2012, when several genetic differences were discovered which classified this snake as its own species. To elucidate the toxicity of venom from this poorly studied colubrid, various biological activities were compared between the venom from the two snake species. The components of their venom were compared by the elution profiles of reversed-phase HPLC and SDS-PAGE, and gel filtrated fractions were tested for effects on blood coagulation. Proteolytic activities of these fractions were also assayed by using synthetic substrates, fibrinogen, and matrix proteins. Similar to the $R$. tigrinus venom, the higher molecular weight fraction of $R$. lateralis venom contained a prothrombin activator. Both prothrombin time (PT) and activated partial thromboplastin time (APTT) of human plasma were shortened by the addition of $R$. lateralis and $R$. tigrinus venom. The thrombin formation was estimated by the uses of SDS-PAGE and chromogenic substrates. These venom fractions also possessed very specific proteinase activity on human fibrinogen, but the substrates for matrix metalloproteinase, such as collagen and laminin, were not hydrolyzed. However, there were some notable differences in reactivity to synthetic substrates for matrix metalloproteinase, and R. tigrinus venom possessed relatively higher activity. Our chemical investigation indicates that the components included in both venoms resemble each other closely. However, the ratio of components and proteolytic activity of some ingredients are slightly different, indicating differences between two closely-related snakes.
\end{abstract}

Keywords: Rhabdophis tigrinus; Rhabdophis lateralis; snake venom; prothrombin activator; blood coagulation 


\section{Introduction}

Rhabdophis lateralis, a colubrid snake, has been considered to be subspecies of $R$. tigrinus, but has been recently reclassified as a different species by special reference to prominent geographical differentiation of the mitochondrial cytochrome $b$ gene in Japanese populations [1]. R. lateralis is distributed over the Asian continent (primarily found in China) [2], whereas R. tigrinus (Yamakagashi) is widely distributed in Japan (exclusive of the northern island, Hokkaido). Both snakes are venomous snakes living in lowlands of rice paddies and watersides and aquatic animals. Especially in Japan, the number of individuals is decreasing, due to the influence of human development [3]. Because this snake has no grooved fangs, envenomation does not occur in most bites; therefore, this snake has long been considered non-venomous [3]. Although R. tigrinus bites induces life-threatening injuries, their mechanism and treatment have not been examined because of an extremely rare incidence of severe cases, compared with that of bites from G. blomhoffii and P. flavoviridis. Our former survey indicated that the pathophysiology of $R$. tigrinus bites was considered disseminated intravascular coagulation (DIC), with a fibrinolytic phenotype. However, the details of coagulation markers remain unknown. Moreover, although antivenom therapy prepared from hyper immunized horses (antivenin serum therapy) is established against $R$. tigrinus bites, sufficient information regarding antivenom therapy has not been provided in clinical practice [4,5]. Both snakes were listed in the WHO guidelines for the worldwide distribution of medically important venomous snake [6]. R. tigrinus antivenom was experimentally manufactured by horses, and is supported by Health Science Grants (1998-1999) from the Ministry of Health, Labour and Welfare in 2000 [3]. R. tigrinus venom is secreted from the Duvernoy's gland, which is connected to the maxillary region immediately forward of the rearmost teeth. In the case of a rear-fanged snake such as $R$. tigrinus, it is difficult to collect much venom from a single snake, because there is no organ storing secreted venom, even if there is a venom gland. Furthermore, there is only one opportunity to collect venom from a single snake, because venom extraction must be carried out after euthanizing a snake, and separating the poison gland. On the other hand, in the case of front-fanged snake with poison bags, it is possible to collect venom without killing the snake by pressing the poison bag existing at the base of the fangs. In addition, multiple poisoning is possible from the front-fanged snake, by leaving the snake for a certain period of time. Due to this venom-secretory mechanism, it is very difficult to collect a large amount of venom to produce antivenom. We examined the possibility to use the venom of $R$. lateralis, that is widespread in China, for the antivenom production. For this purpose, a comparative analysis of the venoms of $R$. lateralis and R. tigrinus was carried out. In our analysis, a prothrombin activator, metalloproteinase, and cysteine-rich secretory protein (CRISP) were all identified as the venom components in both species, and some of their characteristics, such as venom toxicity, the proof of prothrombin activator and metalloproteinase, have been studied [6-11]. To elucidate the toxicity of $R$. lateralis venom, we tested various biological activities and compared their characteristics with $R$. tigrinus venom. Since colubrid venom is not well studied, as compared with the venom of front-fanged snakes such as Sistrurus miliarius barbourin and Ophiophagus hannah, our study contributes to the enhancement of knowledge of the venom proteomics of rear-fanged snakes $[12,13]$.

\section{Results and Discussion}

\subsection{Comparison of the Venom Components}

Crude venom of $R$. tigrinus and $R$. lateralis showed a similar electrophoresis pattern on SDS-PAGE, and in both cases, a band was observed with a molecular mass of $25 \mathrm{kDa}$ (Figure $1 \mathrm{~A}$ ). On the other hand, in the molecular mass range of 37 to $150 \mathrm{kDa}$, similar bands were observed, but the densities of the bands appeared different.

When $R$. lateralis venom was applied to a gel filtration column, a similar elution pattern to $R$. tigrinus venom was obtained (Figure 1B). Several proteins which have the molecular mass of 50-150 kDa were observed on the SDS-PAGE of fraction 1 of both venoms (data not shown). 
Additionally, it was shown that protein of molecular mass $25 \mathrm{kDa}$ was included in fraction 2 . Coagulation activity for rabbit plasma was found in fraction 1 of both species.

The HPLC elution profiles indicate that the composition of both venoms is essentially the same, but found to be different in content (Figure 1C). The main peaks found in both venoms near 19 min of elution time were thought to be "tigrin" as determined from an $N$-terminal sequence analysis. It was also found that the band with molecular mass of $25 \mathrm{kDa}$ is, indeed, tigrin from SDS-PAGE analysis (Figure 1A). Tigrin belongs to the CRISP (snake venom cysteine-rich secretory protein) family, which is widely distributed in various snake venoms, and that they inhibit smooth muscle contraction and cyclic nucleotide-gated ion channels $[10,11]$.
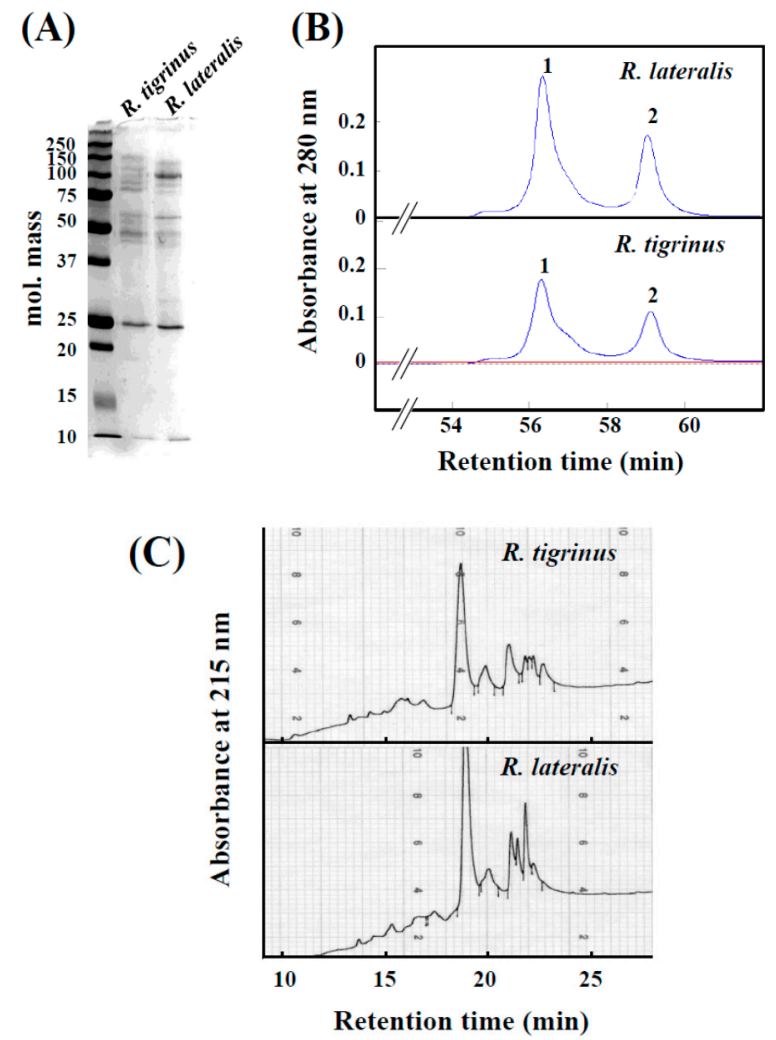

Figure 1. Comparison of crude venoms of $R$. tigrinus and $R$. lateralis. (A) SDS-PAGE of crude venoms; (B) Elution profiles from gel filtration column. Two milligrams of crude venoms were applied to the column and eluted with $0.01 \mathrm{M}$ Tris- $\mathrm{HCl}$ buffer $(\mathrm{pH} 7.2)$ at a flow rate of $1.0 \mathrm{~mL} / \mathrm{min}$; (C) Elution profiles from a reversed-phase-HPLC column were obtained with a linear gradient from $20 \%$ to $90 \%$ acetonitrile over $25 \mathrm{~min}$, with at a flow rate of $1.0 \mathrm{~mL} / \mathrm{min}$.

\subsection{Effect on the Blood Coagulation System}

\subsubsection{Clotting Time of Human Plasma}

R. tigrinus venom is well known to have strong clotting effects $[7,8]$. The existence of a prothrombin activator in the venom has been reported, and its activation mechanism was partially studied by Morita et al. [8]. To confirm whether $R$. lateralis venom provides a similar effect on the blood coagulation system, plasma clotting time was compared with $R$. tigrinus venom. As shown in Table 1, coagulation of human plasma was observed by the addition of venom $(5 \mu \mathrm{g})$, and clotting time of 10 times diluted human plasma was measured to be $155 \mathrm{~s}$ and $168 \mathrm{~s}$, respectively. The prothrombin time (PT), which evaluates the extrinsic pathway of coagulation, was also measured in the absence and presence of venom. The PT was shortened to $25 \mathrm{~s}$ from $33 \mathrm{~s}$ in the presence of venoms, and the difference was not found in the effects of both venoms. The activated partial thromboplastin time (APTT) in contrast 
to the PT, measures the activity of the intrinsic and common pathways of coagulation. The APTT was also decreased to $46-48 \mathrm{~s}$ from $109 \mathrm{~s}$ by the addition of venoms. Since each of PT and APTT was affected by both venoms, similar coagulation factors must be included in both $R$. tigrinus and $R$. lateralis venoms. Compared to other colubrid venom, $R$. tigrinus and $R$. lateralis venom possessed stronger clotting activity. Also, it is reported that some colubrid do not have prothrombin activator [14-18].

Table 1. Coagulation assay of human plasma.

\begin{tabular}{|c|c|c|}
\hline Assay Condition & \multicolumn{2}{|c|}{ Clotting Time (s) * } \\
\hline \multicolumn{3}{|l|}{ Control $(10 \times$ normal plasma) } \\
\hline Prothrombin time $^{\dagger}$ & \multirow{2}{*}{\multicolumn{2}{|c|}{$\begin{array}{c}33 \pm 1.2 \\
109 \pm 0.8\end{array}$}} \\
\hline Activated partial thromboplastin time $\ddagger$ & & \\
\hline Plasma $(10 \times)+5 \mu \mathrm{g}$ of Venom & R. tigrinus & R. lateralis \\
\hline Clotting time without reagents $\S$ & $155 \pm 3.7$ & $168 \pm 11.1$ \\
\hline Prothrombin time $^{\dagger}$ & $25 \pm 0.5$ & $25 \pm 0.5$ \\
\hline Activated partial thromboplastin time $\ddagger$ & $48 \pm 4.5$ & $46 \pm 3.3$ \\
\hline
\end{tabular}

* The data shown represent the average of three experiments $\pm \mathrm{SD} .{ }^{\dagger}$ Prothrombin time was measured by adding $50 \mu \mathrm{L}$ of thromboplastin reagent into the 10 times diluted human plasma in the absence and presence of venom. $\ddagger$ Activated partial thromboplastin time was assayed by adding $50 \mu \mathrm{L}$ of APTT reagent and $50 \mu \mathrm{L} \mathrm{CaCl}$ solution subsequently into the 10 times diluted plasma in the absence and presence of venom. ${ }^{\S}$ Clotting time was determined simply by adding venom.

\subsubsection{Effect of Venom on Degradation of Prothrombin and Fibrinogen}

The time course of prothrombin degradation is shown in Figure 2. Both venoms hydrolyzed prothrombin, and the band of approximately $35 \mathrm{kDa}$ appeared, suggesting that thrombin was formed within $10 \mathrm{~min}$. At the same time, the bands which estimated to be $N$-terminal fragment 1 and fragment 2 of prothrombin were also detected. The activation process of prothrombin by $R$. tigrinus venom had been reported by Morita et al. [8]. The degradation of prothrombin caused by $R$. lateralis venom was delayed approximately $10 \mathrm{~min}$ compared to $R$. tigrinus venom, but the final products were almost equivalent. These results indicate that the effects of prothrombin activators in both venoms are considered to be the same. Regarding the degradation of prothrombin and fibrinogen, there are several reports that colubrid snake containing $R$. tigrinus and R. lateralis, to a greater or lesser extent, has these activities [14-18].

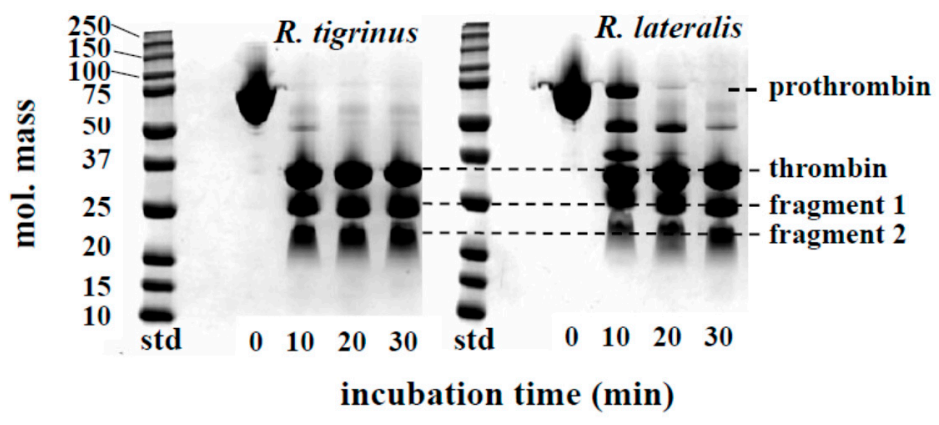

Figure 2. Time course of prothrombin degradation by $R$. tigrinus and $R$. lateralis venom. A mixture of human prothrombin $(0.5 \mathrm{mg})$ and crude venom $(5 \mu \mathrm{g})$ in a total volume of $110 \mu \mathrm{L} 0.05 \mathrm{M}$ Tris-HCl buffer, $\mathrm{pH} 7.5$, containing $0.1 \mathrm{M} \mathrm{NaCl}$ was incubated at $37^{\circ} \mathrm{C}$. At the time intervals indicated, aliquots of the mixture were subjected to SDS-PAGE under unreduced conditions.

For further confirmation that thrombin was formed, the hydrolytic activity was examined by using chromogenic substrates S-2238 for thrombin and S-2222 for factor Xa. Briefly, these substrates were added to the mixture of plasma and venom fraction 1 (Figure 1B), as described in Section 4. 
The mixture of normal plasma and fraction 1 of both venoms remarkably hydrolyzed S-2238, but most of S-2222 was not hydrolyzed (Table 2). These data indicate that thrombin had been formed in the mixture, and factor Xa was not formed. When factor II (prothrombin)-deficient plasma was used for the assay, the hydrolysis amount of S-2238 was clearly decreased from 1001.7 to 170.0 (R. tigrinus) and from 1493.4 to 214.0 (R. lateralis), respectively. As to the reason of some hydrolysis activity of S-2238 under these conditions, a trace of factor II (prothrombin) ( $<3 \%$ of normal plasma) might exist in plasma. When the venom fraction 2 was used for the assay, these substrates were not hydrolyzed. Regarding other colubrids, there is no report that measured hydrolysis activity using the substrates which we used in this study [14-18].

Table 2. Thrombin and factor Xa formation assay from human plasma.

\begin{tabular}{|c|c|c|}
\hline \multirow{3}{*}{ Substrate } & \multicolumn{2}{|c|}{ Activity $\left(\Delta \mathrm{A}_{405 \mathrm{~nm}} / \mathrm{min} / \mathrm{mg}\right.$ Protein $)$} \\
\hline & R. tigrinus & R. lateralis \\
\hline & Fraction 1 & Fraction 1 \\
\hline \multicolumn{3}{|l|}{ normal plasma } \\
\hline $\mathrm{S}-2222 *$ & 3.2 & 4.2 \\
\hline $\mathrm{S}-2238^{+}$ & 1001.7 & 1493.4 \\
\hline \multicolumn{3}{|c|}{ factor II-deficient plasma $\ddagger$} \\
\hline S-2238 & 170.0 & 214.0 \\
\hline
\end{tabular}

The effect of venom fraction 1 on the blood coagulation system was also measured by using human fibrinogen. Although the A $\alpha$ chains of fibrinogen were rapidly hydrolyzed by R. tigrinus and $R$. lateralis venoms, $\mathrm{B} \beta$ and $\gamma$ chains were not degraded (Figure 3). As to the time course of fibrinogen degradation by colubrid venom, Philodryas patagoniensis possessed stronger activity than both $R$. tigrinus and $R$. lateralis [16]. It is not clear now what these fibrinogenolytic effects are due to, but a proteolytic activity described in a later part of this paper (Section 2.3) may be associated with these phenomena.

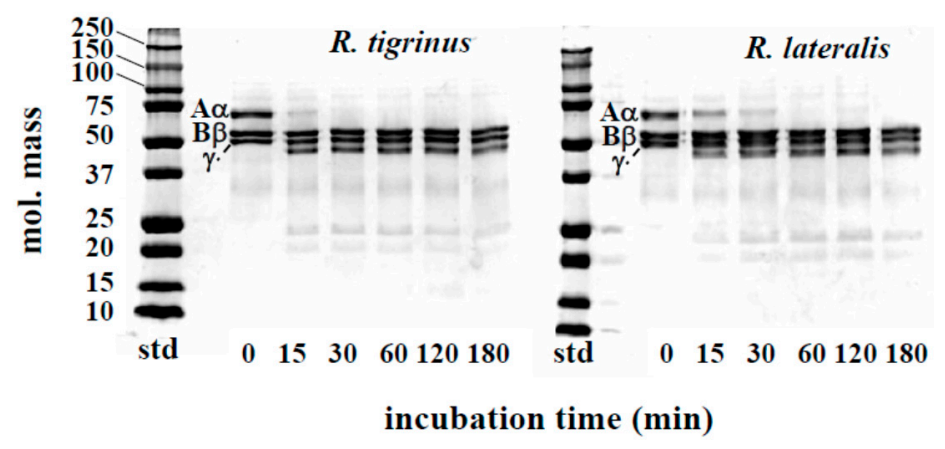

Figure 3. Time course of fibrinogen degradation by R. tigrinus and R. lateralis venom. A mixture of human fibrinogen $(0.1 \mathrm{mg})$ and venom fraction $1(5 \mu \mathrm{g})$ in a total volume of $150 \mu \mathrm{L} 0.01 \mathrm{M}$ Tris- $\mathrm{HCl}$ buffer, $\mathrm{pH} 7.5$, containing $0.1 \mathrm{M} \mathrm{NaCl}$, was incubated at $37^{\circ} \mathrm{C}$. At the time intervals indicated, aliquots of the mixture were subjected to SDS-PAGE under reduced conditions.

From the mentioned results, the strong blood clotting effect of $R$. lateralis venom is thought to be due to prothrombin activation in the same way as $R$. tigrinus venom. In addition, the fibrinogenolytic activity found in both venoms might aggravate the disturbance of the blood coagulation system more. 


\subsection{Proteolytic Activity}

\subsubsection{Effects of Venom Fractions on Synthetic Substrates}

Fluorescence quenching substrates designed for matrix metalloproteinase (MMP) were employed to determine the proteolytic activities of venom fractions (Table 3). NFF-2 and NFF-3 are the substrates for stromelysin-1 (MMP3), and 3163v is for matrilysin (MMP7). NFF-3 and 3163v were hydrolyzed by fraction 1 of both venoms. Fraction 1 from $R$. lateralis venom also possessed hydrolytic activity on NFF-2, however, the effect of $R$. tigrinus venom on this substrate was relatively low. The proteolytic activity for these substrates was not found in fraction 2 of either venom.

Table 3. Proteolytic activity of venom fractions on fluorescence-quenching substrate for matrix metalloproteinases.

\begin{tabular}{ccccc}
\hline \multirow{2}{*}{ Substrate } & \multicolumn{3}{c}{ Proteolytic Activity (nmole Substrate Hydrolyzed/min/mg Protein) } \\
\cline { 2 - 5 } & \multicolumn{2}{c}{ R. tigrinus } & \multicolumn{2}{c}{ R. lateralis } \\
\cline { 2 - 5 } & Fraction 1 & Fraction 2 & Fraction $\mathbf{~}$ & Fraction 2 \\
\hline NFF-2 $^{*}$ & 0.043 & 0 & 0.327 & 0 \\
NFF-3 $^{\dagger}$ & 0.441 & 0 & 0.283 & 0 \\
3163v & 0.431 & 0.010 & 1.287 & 0 \\
\hline MCA (7-methoxycoumarin-4-yl)acetyl)-Arg-Pro-Lys-Pro-Tyr-Ala-Nva-Trp-Met-Lys(Dnp)-NH ${ }_{2}{ }^{\dagger}{ }^{\mathrm{MCA}-A r g-}$
\end{tabular}

\subsubsection{Effects of Venom Fractions on Extracellular Matrix Proteins}

Collagen type IV and laminin are the most common proteins found in the extracellular matrix and constitute the basement membrane. Therefore, the degradation of collagen by snake venom is important in the generation of necrosis. Since fraction 1 hydrolyzed NFF-3, the proteolytic activity for collagen type IV and laminin (substrates of MMP3) were also examined. However, degradation of these matrix proteins was not observed (data not shown). These results indicate that the proteolytic effects of venom components are substrate-specific, and only prothrombin and fibrinogen are hydrolyzed efficiently. Since the small molecular weight peptides were easily affected by proteases, hydrolysis of synthetic substrates may have been observed (Table 3). Compared to R. tigrinus and R. lateralis, other colubrids had variety of proteolytic activities such as caseinase, kallikrein, collagenase, and exopeptidase, etc. [15,16].

\subsubsection{Comparison of Proteolytic Specificity}

Since the comparison of the cleavage sites of the oxidized insulin B chain had been used to examine specificity of various proteinases, this substrate was employed to determine the cleavage specificity of both venoms. The digested peptide fragments formed by the fraction 1 of both venoms were separated with reversed-phase HPLC and analyzed by MALDI-TOF MS. The amino-terminal sequences of digested fragments were also determined (Table 4).

When the fraction 1 of $R$. tigrinus venom was incubated with the insulin B chain, four fragments were obtained by reversed-phase HPLC. Two cleavage sites were determined from the analyzed data and they were Ala(14)-Leu(15) and Tyr(16)-Leu(17). Fraction 1 of $R$. lateralis venom also cleaved the same sites, however, additional cleavage sites of His(10)-Leu(11), Leu(17)-Val(18), and Val(18)-Cys(19) were observed. These results clearly show that there is some difference between $R$. tigrinus and $R$. lateralis venoms. Since $R$. lateralis venom hydrolyzed more MMP substrates nonspecifically (Table 3), and degraded the insulin B chain in more sites, this venom may possess a stronger influence for tissues by actual envenomation. 
Table 4. Molecular mass and $N$-terminal amino acid sequence of digestion fragments of oxidized insulin B chain *.

\begin{tabular}{|c|c|c|c|c|}
\hline \multirow{2}{*}{ Digested Fragment } & \multicolumn{2}{|c|}{ By R. tigrinus Fraction 1} & \multicolumn{2}{|c|}{ By R. lateralis Fraction 1} \\
\hline & $m / z^{\dagger}$ & $N$-terminal Sequence $\ddagger$ & $m / z^{\dagger}$ & $N$-terminal Sequence $\ddagger$ \\
\hline fragment 1 & n.d. ${ }^{\#}$ & - & 1189.5 & F V N \\
\hline fragment 2 & 1601.9 & F V N & 1601.8 & F V N \\
\hline & & & 1522.7 & V C G \\
\hline fragment 3 & n.d. ${ }^{\#}$ & - & 1423.7 & C GE \\
\hline fragment 4 & 1635.8 & L V C & 1635.7 & L V C \\
\hline fragment 5 & 1878.1 & F V N & 1877.9 & F V N \\
\hline fragment 6 & 1912.0 & L Y L & 1911.9 & L Y L \\
\hline
\end{tabular}

${ }^{*}$ Oxidized insulin B chain; Phe-Val-Asn-Gln-His-Leu-Cys $\left(\mathrm{SO}_{3} \mathrm{H}\right)-\mathrm{Gly}-\mathrm{Ser}-\mathrm{His}-\mathrm{Leu}-\mathrm{Val}-\mathrm{Glu}-\mathrm{Ala}-\mathrm{Leu}-\mathrm{Tyr}-\mathrm{Leu}-$ Val-Cys $\left(\mathrm{SO}_{3} \mathrm{H}\right)-$ Gly-Glu-Arg-Gly-Phe-Phe-Tyr-Thr-Pro-Lys-Ala. ${ }^{+}$Mass-to-charge ratio obtained from MALDI-TOF MS spectral analysis. ‡ The amino-terminal residues were analyzed by a Procise protein sequencing system. " n.d.; fragment was not detected.

\section{Conclusions}

It is shown that the composition of R. lateralis venom is similar to that of R. tigrinus; however, some differences were clearly shown in our investigation. The presence of prothrombin activator, proteinase with fibrinogenolytic activity and CRISP were found in both venoms. There are few reports about the clinical damage caused by an envenomation of $R$. lateralis. However, the venom components described in this study had a profound effect on the blood coagulation system, thus, a serious pathologic effect may occur if its venom is injected into a blood vessel. It is fortunate that there is a common antigen, although the two venoms have some differences, such as Protobothrops flavoviridis and Protobothrops elegans [19]. This is important from the viewpoint of colubrid snakebite treatment. Based on the results of this study, it was suggested that the possibility of using $R$. lateralis venom was opened as an immunogen of $R$. tigrinus antivenom, but there are many items to be confirmed in the future.

\section{Materials and Methods}

\subsection{Materials}

Crude $R$. tigrinus venom was obtained from the Japan Snake Institute, because $R$. tigrinus is the only species from that genus Rhabdophis in Japan. On the other hand, several kinds of Rhabdophis inhabit China, but only $R$. lateralis is found within the Shanghai circumference. $R$. lateralis were collected by Dr. Jiuru Sun of the Shanghai Serum Bio-tech Co., Ltd. (Shanghai, China) within two weeks. R. lateralis venom was extracted immediately after collecting snakes at the company's laboratory. Prior to the collection of venom, the snakes were given only water without feeding to avoid any potential effect of feeding on venom composition. To obtain crude venom, we had done following three steps: (1) Collect the relatively large $16 R$. lateralis wild snakes and 20 R. tigrinus wild snakes with a body length of around $1 \mathrm{~m}$ and identify each snake sample. At that time, we only identify the type of snake, we have not confirmed sex, age etc.; (2) Extract Duvernoy's gland from euthanized snakes and rapidly freeze it; (3) Extract with physiological saline, lyophilize to extract the extracted venoms for each type of snake, and put together for long term storage.

Standard human plasma was purchased from Siemens Healthcare Diagnostics Products GmbH (Marburg, Germany) and congenital factor II-deficient plasma was from George King Bio-Medical, Inc. (Overland Park, KS, USA). Rabbit plasma for plasma coagulant assay was the product of Eiken Chemical Co., Ltd. (Tokyo, Japan). In vitro diagnostic reagents for determination of prothrombin time; Coagpia ${ }^{\circledR}$ PT-N, and for activated partial thromboplastin time; Coagpia ${ }^{\circledR}$ APTT-N were the products from Sekisui Medical Co., Ltd. (Tokyo, Japan). Human fibrinogen and oxidized insulin B chain were supplied by Sigma-Aldrich Co., Ltd. (Dorset, UK), and human prothrombin was from Enzyme Research Laboratories Inc. (South Bend, IN, USA). Laminin was obtained from Wako Pure Chemical Industries Ltd. 
(Osaka, Japan), and collagen type IV was from Nitta Gelatin Inc. (Osaka, Japan). Chromogenic substrate for factor Xa; S-2222 (Bz-Ile-Glu-Gly-Arg- $p$ NA) and substrate for thrombin; S-2238 (H-D-Phe-Pip-Arg- $p$ NA) were the products of Chromogenix (West Chester, OH, USA). The fluorescence-quenching substrate for matrix metalloproteinases; NFF-2 (MCA-Arg-Pro-Lys-Pro-Tyr-Ala-Nva-Trp-Met-Lys(Dnp)- $\mathrm{NH}_{2}$ ), NFF-3 (MCA-Arg-Pro-Lys-Pro-Val-Glu-Nva-Trp-Arg-Lys(Dnp)-NH 2 ), 3163v (MCA-Pro-Leu-GlyLeu-Dpa-Ala-Arg- $\mathrm{NH}_{2}$ ), and the reference compound MOCAc-Pro-Leu-Gly were purchased from Peptide Institute, Inc. (Osaka, Japan). $\alpha$-Cyano-4-hydroxycinnamic acid (HCCA), a matrix substance for MALDI-TOF MS and peptide calibration standard were obtained from Bruker Daltonics (Yokohama, Japan). Other chemicals used were of analytical grade and purchased from commercial sources. A gel filtration column, Enrich SEC 70, for BioLogic DuoFlow system was obtained from Bio-Rad Laboratories, Inc. (Hercules, CA, USA), and Develosil ${ }^{\mathrm{TM}}$ ODS-HG-5 $(4.6 \times 250 \mathrm{~mm})$ for reversed-phase HPLC was from Nomura Chemical Co., Ltd. (Seto, Japan).

\subsection{Fractionation of Crude Venom}

Crude venoms of R. tigrinus and R. lateralis ( $2 \mathrm{mg}$ each) were applied to an Enrich SEC 70 gel filtration column $(10 \times 300 \mathrm{~mm})$ which was connected to a BioLogic DuoFlow system, and eluted with $0.01 \mathrm{M}$ Tris- $\mathrm{HCl}$ buffer (pH 7.2) at a flow rate of $1.0 \mathrm{~mL} / \mathrm{min}$. Crude venoms were also fractionated by a reversed-phase HPLC column (ODS-HG-5) equilibrated with $0.1 \%$ trifluoroacetic acid in $80 \%$ $\mathrm{H}_{2} \mathrm{O}$ and $20 \%$ acetonitrile. Elution was achieved over $25 \mathrm{~min}$ with a linear gradient from $20 \%$ to $90 \%$ acetonitrile, at a flow rate of $1.0 \mathrm{~mL} / \mathrm{min}$.

\subsection{Blood Coagulation Assays}

According to the instruction manual of the supplier, prothrombin time (PT) and activated partial thromboplastin time (APTT) were measured. To measure excessive coagulation exactly, diluted human plasma was used for these assays. Fifty microliters of human plasma and appropriate concentration of venom fractions in $0.45 \mathrm{~mL}$ of saline were mixed and kept at $37^{\circ} \mathrm{C}$. PT was measured by adding $50 \mu \mathrm{L}$ of thromboplastin reagent into the mixture described above. APTT was assayed by adding $50 \mu \mathrm{L}$ of APTT reagent and $50 \mu \mathrm{L} \mathrm{CaCl}_{2}$ solutions subsequently into the plasma-venom mixture. The assay process was conducted according to the instructions of the manufacturer and performed at $37^{\circ} \mathrm{C}$.

The hydrolytic activity for blood coagulation factors of venom fraction was measured by using chromogenic substrates [20,21]. Briefly, $50 \mu \mathrm{L}$ of venom solution was added to the mixture of plasma $(50 \mu \mathrm{L}), 50 \mathrm{mM}$ Tris-HCl buffer (pH 8.3) containing $227 \mathrm{mM} \mathrm{NaCl}(360 \mu \mathrm{L})$, and $0.5 \mathrm{M} \mathrm{CaCl}_{2}(50 \mu \mathrm{L})$. After the incubation for $1 \mathrm{~min}$ at $37^{\circ} \mathrm{C}, 0.5 \mathrm{~mL}$ of $1.59 \mathrm{mM}$ substrate solution was added and the rate of pNA formation was determined by measuring the increase in absorbance per min at $405 \mathrm{~nm}$.

\subsection{Proteolytic Activities}

The hydrolytic activity for matrix metalloproteinase was assayed by using synthetic fluorescence quenching substrates [22,23]. Substrates were prepared as $10 \mathrm{mM}$ stock solutions in dimethyl sulfoxide. Assay was carried out by incubating $5 \mu \mathrm{L}$ of substrate stock solution with $10 \mu \mathrm{L}$ of venom fraction in $50 \mathrm{mM}$ Tris- $\mathrm{HCl}$ buffer (pH 7.5) containing $0.15 \mathrm{M} \mathrm{NaCl}, 10 \mathrm{mM} \mathrm{CaCl}_{2}, 0.05 \%$ Brij 35, and $0.02 \%$ $\mathrm{NaN}_{3}$. The reaction was stopped by the addition of $0.9 \mathrm{~mL}$ of $3 \%$ acetic acid, and the intensity of fluorescence was measured at $\lambda_{\mathrm{ex}}$ of $325 \mathrm{~nm}$ and $\lambda_{\mathrm{em}}$ of $393 \mathrm{~nm}$. The amount of substrate hydrolyzed was calculated from the standard curve of the reference compound, MOCAc-Pro-Leu-Gly.

The effect of venom on human prothrombin, fibrinogen, collagen, and laminin were measured by monitoring the time course degradation of these proteins on SDS polyacrylamide gel. Oxidized insulin B chain was used for the determination of enzyme specificity. Briefly, the hydrolyzed peptides were fractionated by a reversed-phase HPLC column (Develosil 300 ODS-7), and the fragments were identified by MALDI-TOF MS spectrum using Autoflex speed (Bruker Daltonics). The $N$-terminal amino acid sequence of each fragment was also detected by a Procise protein sequencing system (Applied Biosystems, Foster City, CA, USA). 
Acknowledgments: This work was supported by the Research Program on Emerging and Re-emerging Infectious Disease from the Japan Agency for Medical Research and Development (AMED). The authors are grateful to Ryoko Takeyama for her technical help.

Author Contributions: This work was carried out in collaboration of all authors. Y.K. and T.N. designed the study. Y.K. also performed the protein analysis, blood coagulation assays, and wrote the first draft of the manuscript. T.H. and A.S. offered the data about the epidemiology of snake bite, and clinical manifestations of envenomation by $R$. tigrinus. A.Y. and A.S. were concerned with venom sampling and supply, and gave information regarding the venom components. M.A. and K.S. participated and cooperated with the research group and revised the manuscripts. All authors read and approved the final manuscript.

Conflicts of Interest: The authors declare no conflict of interest.

\section{References}

1. Takeuchi, H.; Ota, H.; Oh, H.-S.; Hikida, T. Extensive genetic divergence in the East Asian natricine snake, Rhabdophis tigrinus (Serpentes: Colubridae), with special reference to prominent geographical differentiation of the mitochondrial cytochrome $b$ gene in Japanese populations. Biol. J. Linn. Soc. Lond. 2012, 105, 395-408. [CrossRef]

2. Uetz, P.; Hallermann, J. The Reptile Database. Zoological Museum Hamburg. Available online: https: / / reptile-database.reptarium.cz/species?genus=Rhabdophis\&species=tigrinus (accessed on 19 July 2017).

3. Morokuma, K.; Kobori, N.; Fukuda, T.; Uchida, T.; Sakai, A.; Toriba, M.; Ohkuma, K.; Nakai, K.; Kurata, T.; Takahashi, M. Experimental manufacture of equine antivenom against Yamakagashi (Rhabdophis tigrinus). Jpn. J. Infect. Dis. 2011, 64, 397-402. [PubMed]

4. Hifumi, T.; Sakai, A.; Yamamoto, A.; Murakawa, M.; Ato, M.; Shibayama, K.; Ginnaga, A.; Kato, H.; Koido, Y.; Inoue, J.; et al. Clinical characteristics of yamakagashi (Rhabdophis tigrinus) bites: A national survey in Japan, 2000-2013. J. Intensiv. Care 2014, 2, 19. [CrossRef] [PubMed]

5. Sakai, A. Diagnosis and treatment of snakebite by Mamushi and Yamakagashi. Chudoku Kenkyu 2013, 26, 193-199. [PubMed]

6. World Health Organization. Guidelines for the Production, Control and Regulation of Snake Antivenom Immunoglobulins; Replacement of Annex 2 of WHO Technical Report Series, No. 964; World Health Organization: Geneva, Switzerland, 2017.

7. Sakai, A.; Honma, M.; Sawai, Y. Study on the toxicity of venoms extracted from Duvernoy's gland of certain Asian Colubrid snakes. Snake 1984, 16, 16-20.

8. Morita, T.; Matsumoto, H.; Iwanaga, S.; Sakai, A. A prothrombin activator found in Rhabdophis tigrinus tigrinus (Yamakagashi Snake) venom. In Hemostasis and Animal Venoms; Pirkle, H., Markland, F.S., Jr., Eds.; Marcel Dekker, Inc.: New York, NY, USA, 1988; pp. 55-66.

9. Komori, K.; Konishi, M.; Maruta, Y.; Toriba, M.; Sakai, A.; Matsuda, A.; Hori, T.; Nakatani, M.; Minamino, N.; Akizawa, T. Characterization of a novel metalloproteinase in Duvernoy's gland of Rhabdophis tigrinus tigrinus. J. Toxicol. Sci. 2006, 31, 157-168. [CrossRef] [PubMed]

10. Yamazaki, Y.; Koike, H.; Sugiyama, Y.; Motoyoshi, K.; Wada, T.; Hishinuma, S.; Mita, M.; Morita, T. Cloning and characterization of novel snake venom proteins that block smooth muscle contraction. Eur. J. Biochem. 2002, 269, 2708-2715. [CrossRef] [PubMed]

11. Yamazaki, Y.; Morita, T. Structure and function of snake venom cysteine-rich secretory proteins. Toxicon 2004, 44, 227-231. [CrossRef] [PubMed]

12. Juárez, P.; Sanz, L.; Calvete, J.J. Snake venomics: Characterization of protein families in Sistrurus barbouri venom by cysteine mapping, $N$-terminal sequencing, and tandem mass spectrometry analysis. Proteomics 2004, 4, 327-338. [CrossRef] [PubMed]

13. Roy, A.; Zhou, X.; Chong, M.Z.; D’hoedt, D.; Foo, C.S.; Rajagopalan, N.; Nirthanan, S.; Bertrand, D.; Sivaraman, J.; Kini, R.M. Structural and functional characterization of a novel homodimeric three-finger neurotoxin from the venom of Ophiophagus hannah (king cobra). J. Biol. Chem. 2010, 285, 8302-8315. [CrossRef] [PubMed]

14. Sánchez, M.N.; Timoniuk, A.; Maruñak, S.; Teibler, P.; Acosta, O.; Peichoto, M.E. Biochemical and biological analysis of Philodryas baroni (Baron's green racer; Dipsadidae) venom: Relevance to the findings of human risk assessment. Hum. Exp. Toxicol. 2014, 33, 22-31. [CrossRef] [PubMed] 
15. Weinstein, S.A.; Kardong, K.V. Properties of Duvernoy's secretions from opisthoglyphous and aglyphous colubrid snakes. Toxicon 1994, 32, 1161-1185. [CrossRef]

16. Peichoto, M.E.; Leiva, L.C.; Guaimás Moya, L.E.; Rey, L.; Acosta, O. Duvernoy's gland secretion of Philodryas patagoniensis from the northeast of Argentina: Its effects on blood coagulation. Toxicon 2005, 45, 527-534. [CrossRef] [PubMed]

17. Lumsden, N.G.; Ventura, S.; Dauer, R.; Hodgson, W.C. A biochemical and pharmacological examination of Rhamphiophis oxyrhynchus (Rufous beaked snake) venom. Toxicon 2005, 45, 219-231. [CrossRef] [PubMed]

18. Kamiguti, A.S.; Theakstonk, R.D.; Shermanm, N.; Fox, J.W. Mass spectrophotometric evidence for P-III/P-IV metalloproteinases in the venom of the Boomslang (Dispholidus typus). Toxicon 2000, 38, 1613-1620. [CrossRef]

19. Tsai, I.H.; Chen, Y.H.; Wang, Y.M. Comparative proteomics and subtyping of venom phospholipases $\mathrm{A}_{2}$ and disintegrins of Protobothrops pit vipers. Biochim. Biophys. Acta 2004, 1702, 111-119. [CrossRef] [PubMed]

20. Aurell, L.; Friberger, P.; Karlsson, G.; Claeson, G. A new sensitive and highly specific chromogenic peptide substrate for factor Xa. Thromb. Res. 1977, 11, 595-609. [CrossRef]

21. Axelsson, G.; Korsan-Bengtsen, K.; Waldenström, J. Prothrombin determination by means of a chromogenic peptide substrate. Thromb. Haemost. 1976, 36, 517-524. [PubMed]

22. Nagase, H.; Fields, C.G.; Fields, G.B. Design and characterization of a fluorogenic substrate selectively hydrolyzed by stromelysin 1 (matrix metalloproteinase-3). J. Biol. Chem. 1994, 269, 20952-20957. [PubMed]

23. Knigh, C.G.; Willenbrock, F.; Murphy, G. A novel coumarin-labelled peptide for sensitive continuous assays of the matrix metalloproteinases. FEBS Lett. 1992, 296, 263-266. [CrossRef]

(C) 2017 by the authors. Licensee MDPI, Basel, Switzerland. This article is an open access article distributed under the terms and conditions of the Creative Commons Attribution (CC BY) license (http:/ / creativecommons.org/licenses/by/4.0/). 